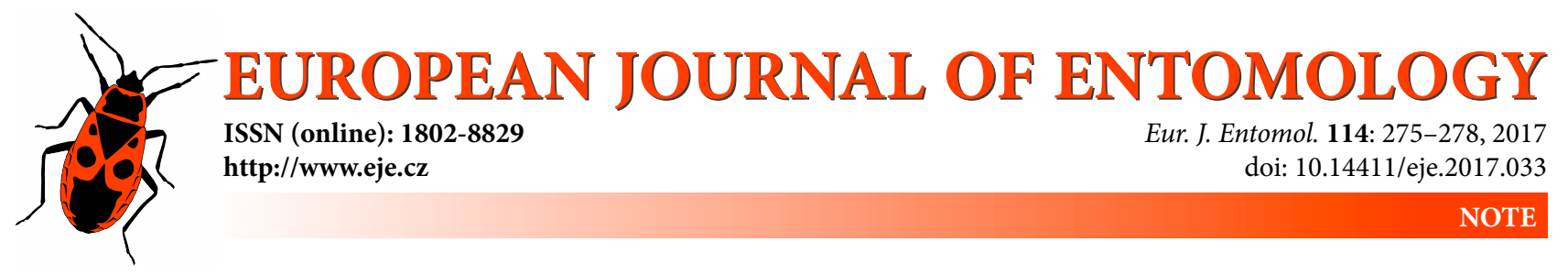

\title{
Protogyny after hibernation and aestivation in Cheilomenes sexmaculata (Coleoptera: Coccinellidae) in central Japan
}

\author{
YASUKO KAWAKAMI ${ }^{1}$, KAZUO YAMAZAKI ${ }^{2}$ and KAZUNORI OHASHI ${ }^{3}$ \\ ${ }^{1}$ Osaka Museum of Natural History, Osaka, Osaka 546-0034, Japan; e-mail: yasukocafius@gmail.com \\ 2 Osaka Institute of Public Health, Osaka, Japan; e-mail: kazuo-yamazaki@iph.osaka.jp \\ ${ }^{3}$ Honmachi, Toyonaka City, Osaka 560-0021, Japan; e-mail: oohasikznr@yahoo.co.jp
}

Key words. Coleoptera, Coccinellidae, Cheilomenes sexmaculata, demography, ladybird beetle, life cycle, mating

Abstract. Differences in the time of occurrence of both sexes of adult ladybirds, which reflect differences in the longevity and reproductive strategies of the sexes, is important from the perspective of applied entomology, including biological control, as well as basic entomology. Nevertheless, there is little field census data on this topic. We investigated the seasonal occurrence of both sexes of Cheilomenes sexmaculata (Fabricius) in Osaka City, central Japan, from 2003 to 2011. Female adults tended to appear earlier than males after hibernation or aestivation. That males never appeared earlier than females during the nine year period of this study indicate that protogyny occurs after hibernation and aestivation in this species.

\section{INTRODUCTION}

Despite the fact that male and female insects should occur simultaneously so that they are more likely to encounter each other for mating, the sexes of many insects differ in their seasonal occurrence. For example, in butterflies in temperate zones, there is a general tendency for males to emerge before females, i.e. protandry (Wiklund \& Fagerström, 1977). In addition, male butterflies, which overwinter as adults, appear earlier than females after hibernation (Wiklund et al., 1996). The occurrence of this pattern could be because monogamous (single-mated) male butterflies that emerge before females are more likely to mate with virgin females than their counterparts that emerge later (Wiklund \& Fagerström, 1977; Iwasa et al., 1983).

In addition, reproductive physiology may constrain the timing of occurrence of both sexes, for example, females maximize their body mass by prolonging development, because generally female fecundity is directly correlated with body size; in contrast, males with a lower body mass may suffer negligible disadvantages during reproduction (Kleckner et al., 1995). Differences in the time of occurrence of both sexes may arise because of differences in the mortality and/or demography of the sexes (Carey et al., 1995). In many species of insects, males emerge concurrently with or before females; however protogyny, in which females appear earlier than males, is recorded in caddisflies and bagworm moths (Degen et al., 2015; Nowinszky et al., 2016). In bagworm moths, protogyny is associated with a reduction in female encounter rates with males; however, as females live longer than males this may compensate for this disadvantage (Degen et al., 2015). Taken together, sexual dimorphism in the timing of emergence is affected by differences in reproductive strategies, reproductive physiology and demographics (e.g. temporal pattern in abundance and mortality) of the sexes.
Many species of ladybirds survive during unfavourable seasons when food is scarce either in diapause or dormancy (Hodek, 2012). Following such periods they are unlikely to be protandrous as there is little competition between males for females, because many ladybirds mate more than once (Hemptinne et al., 2001; Nedvěd \& Honěk, 2012). Since there are very few studies on the phenology of both sexes of ladybirds, we investigated the seasonal occurrence of males and females of Cheilomenes sexmaculata in Osaka City, Japan, from 2003 to 2011. This species is widely distributed across intermediate and equatorial latitudinal regions (Kawakami et al., 2013). In Osaka, adults emerge from hibernation in spring and complete three, or on rare occasions, two generations a year, and adults were not observed in summer during the nine years 2003-2011 (Kawakami et al., 2016). In the present study, we describe the seasonal occurrence of adult ladybirds, focusing on the pattern of occurrence of both sexes, and discuss the factors that lead to the difference in the occurrence of both sexes, which reflect differences in their reproductive strategies and temporal shifts in the abundances of the sexes.

\section{MATERIAL AND METHODS}

To investigate the difference in the occurrence of the sexes and periods of mating activity that may interact with the phenology of both sexes of $C$. sexmaculata, we conducted a field survey in Osaka from March 10, 2003 to December 10, 2011, five to seven times a month. This research was carried out in Nagai Park $\left(34^{\circ} 36^{\prime} \mathrm{N}, 135^{\circ} 30^{\prime} \mathrm{E}\right.$, altitude $10 \mathrm{~m}$, area $\left.65.7 \mathrm{ha}\right)$, which is located in Osaka City, central Japan. We chose a 30-ha area with many planted shrubs. The field surveys were conducted for 1 to $2 \mathrm{~h}$, from 10:00 to 13:00, both on clear and cloudy days. The numbers of mating pairs, larvae, teneral (newly eclosed and thus not fully coloured) adults, and post-teneral adults of both sexes of C. sex- 

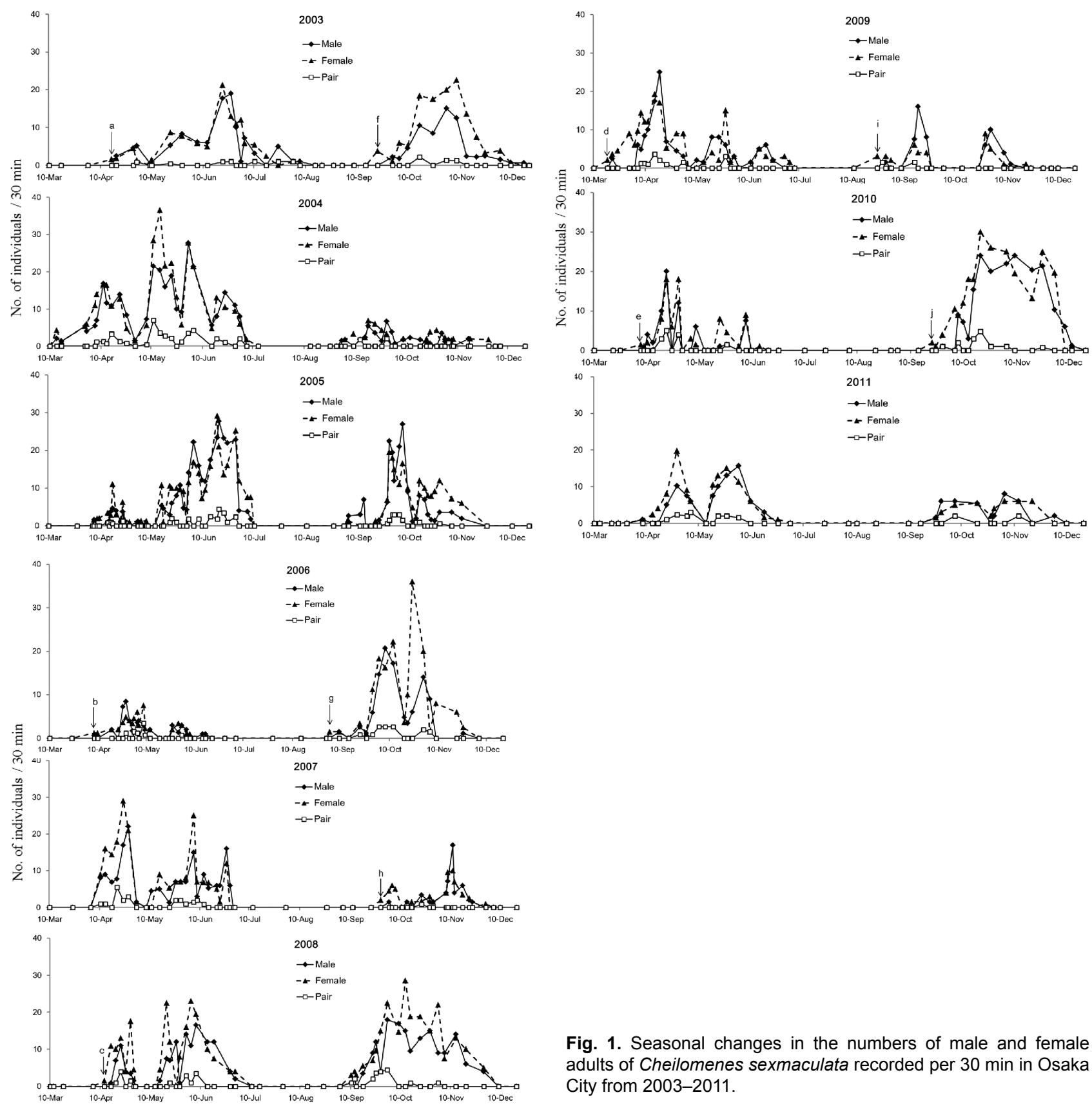

maculata were counted on shrubs and weeds where prey aphids occurred. Using these data, population changes in the abundance of larvae, teneral and post-teneral adults from 2003 to 2011 are described in Kawakami et al. (2016).

To determine the difference in the occurrence and periods of mating activity of the sexes, the average numbers of males, females and mating adults per $30 \mathrm{~min}$ are described using a line diagram. Sex ratio and mating pairs were analyzed using Pearson's correlation coefficients for each year. As C. sexmaculata adults hibernate and aestivate (Kawakami et al., 2016) like other ladybird beetles (Nedvěd \& Honěk, 2012), the demography of both sexes and the sex ratio of the generations that overwinter and oversummer were determined.

\section{RESULTS AND DISCUSSION}

The results of field surveys of the changes in the number of larvae, teneral and post-teneral adults in the Osaka population revealed that $C$. sexmaculata completed three generations a year

Fig. 1. Seasonal changes in the numbers of male and female adults of Cheilomenes sexmaculata recorded per $30 \mathrm{~min}$ in Osaka City from 2003-2011.

from 2003 to 2005 and 2007 to 2009 , but only two generations in 2006, 2010 and 2011 (Kawakami et al., 2016). On the basis of these findings, the generation periods of the adults that overwintered and oversummered from 2003 to 2011 are shown in Table 1. Autumn adults hibernate and emerge as overwintered adults, and summer adults aestivate and emerge as oversummered adults (Kawakami et al., 2016). Differences in the time of occurrence of both sexes may lead to a decline in the mating rate. Therefore, to investigate the time of mating with regard to the abundance of both sexes, the relationship between the number of mating pairs and the number of adults of both sexes was analyzed using Pearson's correlation coefficient. The difference in the sex ratios of the generations that overwintered and oversummered, indicated by a slight protogyny in the line diagram, was examined because a more abundant sex may appear earlier and remain longer than a less abundant sex. Thus, any difference in the sex ratio (male/ male + female) from 0.5 was analyzed using a test for independence for the two generations. We used JMP 11 Discovery (SAS 
Table 1. Dates when Cheilomenes sexmaculata overwintered and oversummered each year in Osaka City from 2003-2011 (modified Kawakami et al., 2016). - denotes no occurrence.

\begin{tabular}{lcc}
\hline Year & Overwintered & Oversummered \\
\hline 2003 & $19 \mathrm{Apr}-9$ May & 21 Sep-9 Oct \\
2004 & $14 \mathrm{Mar}-30 \mathrm{Apr}$ & - \\
2005 & $6 \mathrm{Apr}-4 \mathrm{May}$ & $4 \mathrm{Sep}-17 \mathrm{Sep}$ \\
2006 & $7 \mathrm{Apr}-24 \mathrm{May}$ & $2 \mathrm{Sep}-25 \mathrm{Sep}$ \\
2007 & $12 \mathrm{Apr}-13 \mathrm{May}$ & $28 \mathrm{Sep}-7 \mathrm{Oct}$ \\
2008 & $10 \mathrm{Apr}-8 \mathrm{May}$ & $10 \mathrm{Sep}-13 \mathrm{Sep}$ \\
2009 & $18 \mathrm{Mar}-2 \mathrm{May}$ & $25 \mathrm{Aug}-30 \mathrm{Aug}$ \\
2010 & $6 \mathrm{Apr}-8 \mathrm{May}$ & $22 \mathrm{Sep}-28 \mathrm{Sep}$ \\
2011 & $7 \mathrm{Apr}-5$ May & $25 \mathrm{Sep}-28 \mathrm{Sep}$ \\
\hline
\end{tabular}

Institute Inc., Cary, NC, USA) to carry out all the statistical analyses.

The numbers of male and female $C$. sexmaculata adults and mating pairs recorded per $30 \mathrm{~min}$, from March 10 to December 10 in each year, from 2003-2011, are shown in Fig. 1. A comparison of the first day of occurrence of the adults of both sexes that overwintered revealed that females appeared earlier than males in five years (Fig. 1, 2003: arrow "a", 2006: arrow "b", 2008: arrow "c", 2009: arrow "d", 2010: arrow "e"), three, 11, four, three and four days earlier, respectively (Fig. 1). In addition, comparison of the first day of occurrence of adults that oversummered revealed that females appeared earlier in five years (Fig. 1, 2003: arrow "f", 2006: arrow “g”, 2007: arrow "h", 2009: arrow "i”, 2010: arrow "j"), nine, six, five, three and six days earlier, respectively (Fig. 1). In contrast, both the males that overwintered and oversummered did not appear earlier than females in any year over the period 2003-2011 (Fig. 1). Mating pairs tended to be observed mainly on days when there were many adult individuals of both sexes (Fig. 1). Numbers of adults and mating pairs over the period 2003-2011 were significantly correlated; the correlation coefficients for males and females ranged from 0.1970 to 0.6399 and 0.1995 to $0.6264(P \leq 0.001)$.

Like other ladybird beetles, which hibernate as adults (Nedvěd \& Honěk, 2012), C. sexmaculata adults also hibernate and aestivate (Kawakami et al., 2016). In Osaka female adults tended to appear earlier than males after hibernation and aestivation during the period 2003 to 2011 (Fig. 1). Differences in the day of appearance of both sexes are small; however, the fact that males never appeared earlier than females over the nine year period of this study indicates that protogyny occurs after both hibernation and aestivation in this species. Multiple mating may occur in the Osaka population of $C$. sexmaculata because mating pairs were recorded throughout each year except in summer (Fig. 1) and tended to be recorded on days when there were many adult individuals of both sexes (Fig. 1). Ladybirds often mate several times and the sperm of the last male a female copulates with is used to fertilize the eggs (Katakura, 1981; De Jong et al., 1993, 1998; Ueno, 1994; for the Indian population of this species, see Chaudhary et al., 2016). Therefore, for males there would be few benefits from protandry, which may be one of the factors favouring protogyny in C. sexmaculata. Indeed, for Adalia bipunctata at emergence from pupae reared under laboratory conditions, slight

Table 2. Sex ratios (male/male + female) of the generations of Cheilomenes sexmaculata that overwintered and oversummered in Osaka City from 2003 to 2011. The bias in the sex ratios were analyzed using $x^{2}$-test for independence for the adult numbers of both sexes. $d f=1 ; n$ - sample size.

\begin{tabular}{lcrrc}
\hline Generation & Sex ratio $\left(\sigma^{7}\right)$ & $X^{2}$ value & $p$ value & $n$ \\
\hline Overwintering & 0.4133 & 32.9380 & $<0.0001$ & 1096 \\
Oversummering & 0.3932 & 5.3419 & 0.0208 & 117 \\
\hline
\end{tabular}

protogyny is documented (Hemptinne et al., 2001). Alternatively, for the females to be sexually mature it may be necessary for them to begin feeding on temporary food resources earlier than males.

The sex ratio remained the same throughout this study (Kawakami et al., 2016); however, females that overwintered were significantly more abundant than overwintered males and females that oversummered tended to be more abundant than oversummered males (Table 2). This indicates that the demographic differences between sexes (more females appeared than males in early spring or early autumn) may also contribute to protogyny.

In conclusion, taken together, our findings indicate that protogyny in the Osaka population of $C$. sexmaculata may be due to the rare occurrence of competition between males for females and the differences in the demographics of the sexes.

ACKNOWLEDGEMENTS. We are grateful to the Editor and two anonymous reviewers for their helpful suggestions. We would like to express our special gratitude to M. Okamoto (Osaka Museum of Natural History) for his assistance with the survey.

\section{REFERENCES}

Carey J.R., Liedo P., Orozco D., Tatar M. \& Vaupel J.W. 1995: A male-female longevity paradox in medfly cohorts. $-J$. Anim. Ecol. 64: 107-116.

Chaudhary D.D., Mishra G. \& Omkar 2016: Last male wins the egg fertilization fight: A case study in ladybird, Menochilus sexmaculatus. - Behav. Proc. 131: 1-8.

Degen T., Hovestadt T., Mitesser O. \& Hölker F. 2015: High female survival promotes evolution of protogyny and sexual conflict. — PLoS ONE 10(3): e0118354, 12 pp.

De Jong P.W., Verhoog M.D. \& Brakefield P.M. 1993: Sperm competition and melanic polymorphism in the 2-spot ladybird, Adalia bipunctata (Coleoptera, Coccinellidae). - Heredity 70: 172-178.

De Jong P.W., Brakefield P.M. \& Ceerinck B.P. 1998: The effect of female mating history on sperm precedence in the two-spot ladybird, Adalia bipunctata (Coleoptera, Coccinellidae). Behav. Ecol. 9: 559-565.

Hemptinne J.L., Dixon A.F.G. \& Adam B. 2001: Do males and females of the two-spot ladybird, Adalia bipunctata (L.), differ in when they mature sexually? — J. Insect Behav. 14: 411-419.

HodeK I. 2012: Diapause/dormancy. In Hodek I., van Emden H. F. \& Honěk A. (eds): Ecology and Behaviour of the Ladybird Beetles (Coccinellidae). Wiley-Blackwell, Oxford, pp. 275333.

Iwasa Y., Odendaal J.F., Murphy D.D., Ehrlich P.R. \& Launer A.E. 1983: Emergence patterns in male butterflies: a hypothesis and a test. - Theor. Popul. Biol. 23: 363-379.

KataKura H. 1981: Sperm storage place in adult females of the phytophagous ladybirds belonging to Henosepilachna vigintioctomaculata complex (Coleoptera, Coccinellidae). — Kontyû 49: 477-481.

Kawakami Y., Yamazaki K. \& Ohashi K. 2013: Geographical variations of elytral color polymorphism in Cheilomenes sexmaculata (Fabricius) (Coleoptera: Coccinellidae). — Entomol. Sci. 16: 235-242.

Kawakami Y., Yamazaki K. \& Ohashi K. 2016: Population dynamics, seasonality and aphid prey of Cheilomenes sexmaculata (Coleoptera: Coccinellidae) in an urban park in central Japan. — Eur. J. Entomol. 113: 192-199.

Kleckner C.A., Hawley W.A., Bradshaw W.E., Holzapfel C.M. \& FisHER I.J. 1995: Protandry in Aedes sierrensis: The significance of temporal variation in female fecundity. - Ecology 76: $1242-4250$. 
NEDVĚD O. \& HoNĚK A. 2012: Life history and development. In Hodek I., van Emden H.F. \& Honěk A. (eds): Ecology and Behaviour of the Ladybird Beetles (Coccinellidae). Wiley-Blackwell, Oxford, pp. 54-109.

Nowinszky L., Puskás J. \& Kiss O. 2016: Protandry and protogyny in swarmings of caddisflies (Trichoptera) species in Hungary (Central Europe). - Int. J. Res. Zool. 6: 1-5.

OBRYCKI J.J. \& KRING T.J. 1998: Predaceous Coccinellidae in biological control. - Annu. Rev. Entomol. 43: 295-321.

UENO H. 1994: Intraspecific variation of P2 value in a coccinellid beetle, Harmonia axyridis. - J. Ethol. 12: 169-174.
WIKLUND C. \& FAGERSTRÖM T. 1977: Why do males emerge before females? A hypothesis to explain the incidence of protandry in butterflies. - Oecologia 31: 153-158.

WikLund C., LindFors V. \& Forsberg J. 1996: Early male emergence and reproductive phenology of the adult overwintering butterfly Gonepteryx rhamni in Sweden. — Oikos 75: 227-240.

Received January 18, 2017; revised and accepted April 25, 2017 Published online May 30, 2017 